\title{
In Bewegung bleiben ...
}

Editorial -- Autor:J. Gensichen

\section{Bei aller Dringlichkeit der Corona-Pandemie und der erforderlichen Fokus- sierung unserer aktuellen Arbeit leiden Patienten weiterhin an den sog. großen "Volkskrankheiten“ wie koronare Herzerkrankung oder chronische Herzinsuffizienz. Sie müssen von uns weiterhin gut versorgt werden.}

Dies unterstreichen nicht zuletzt die Hinweise, dass eine COVID-19-Erkrankung auch das kardiovaskuläre System beeinträchtigen kann. Unterstützen wir also unsere Patienten und bestärken wir sie in der evidenzbasierten Kardio-Prävention durch körperliches Training!

Im Beitrag von R. Nebel wird die Relevanz von körperlichem Training bei Patienten mit koronarer Herzerkrankung (KHK) behandelt. Es wird gezeigt, dass neben der Kontrolle der weiteren Risikofaktoren die kardiovaskuläre Prognose der Patienten durch konsequentes körperliches Training deutlich gebessert werden kann. Der Artikel weist darüber hinaus auch auf wichtige sekundäre Ziele des Trainings hin. Heute benötigt man schon gute Gründe, um einem Patienten mit KHK das körperliche Training vorzuenthalten. So vermittelt der Beitrag auch konkrete Planungsschritte für die unmittelbare klinische Umsetzung.

Im Beitrag von A. Preßler werden der klinische Nutzen und die Anwendung des körperlichen Trainings für Patienten mit chronischer Herzinsuffizienz dargestellt. Hintergrund ist hier, dass die Belastbarkeit der betroffenen Patienten (maximale Sauerstoffaufnahme, $\mathrm{VO}_{2}$ peak) erhöht werden kann. Auch dieser Beitrag vermittelt praktische Handlungsempfehlungen, die sich auf die Evidenz, u. a. der European Society of Cardiology (ESC), stützen können.

Beide Artikel unterstreichen die umfassende Bedeutung der kardiovakulären Prävention bzw. ihrer entscheidenden Wirkungsmechanismen, wie sie u. a. auch in der Leitlinie „Hausärztliche Risikoberatung zur kardiovaskulären Prävention“ (Deutsche Gesellschaft für Allgemeinmedizin, DEGAM, Berlin, 2017) oder in der „Nationalen Versorgungsleitlinie Chronische Herzinsuffizienz" (Ärztliches Zentrum für Qualität in der Medizin, ÄZQ, Berlin, 2019) betont wird.

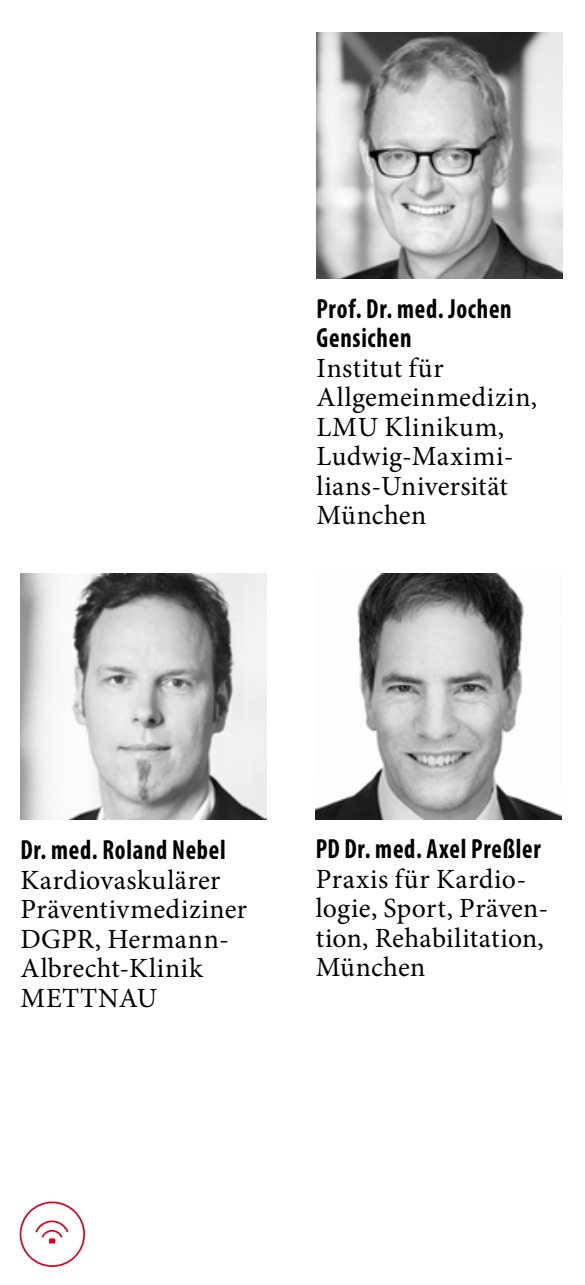

Die Leitlinie „Hausärztliche Risikoberatung zur kardiovaskulären Prävention“ finden Sie unter:

https://www.awmf.org/leitlinien/ detail/II/053-024.html
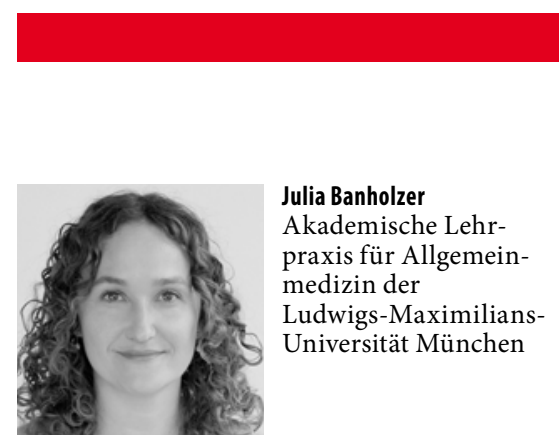

Julia Banholzer

Akademische Lehrpraxis für Allgemeinmedizin der

Ludwigs-Maximilians-

Universität München

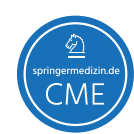

CME: Allgemeinärztliche Sonografie Teil 1: Das Abdomen

Durch Ultraschalluntersuchungen lassen sich oft kostspielige und durch Strahlungseinwirkung belastende diagnostische Überweisungen vermeiden. Ob Leber, Gallenblase, Nieren, Darm, Pankreas oder Milz - die Organe des Bauchraums lassen sich mit der Sonografie gut darstellen und beurteilen.

ab Seite 48

\section{望 Springer Medizin}

